\title{
Exploring Differences In Preference For On-Line Versus Traditional Classroom Delivery Of A Freshmen Introduction To Global Business Course
}

Mark Levine, California State University Chico, USA

Paul Guy, California State University Chico, USA

Peter Straus, California State University Chico, USA

HT Levine, California State University Chico, USA

\begin{abstract}
The present study investigates whether pre-business students, after having completed a traditional in class freshmen introduction to global business course, express a difference in preference for such a course to be delivered online versus classroom or no preference at all. The study further explores whether four variables: 1) number of units of college credit completed, 2) anticipated grade in the class, 3) gender, and 4) age are related to students' preference for mode of instruction.
\end{abstract}

Keywords: On-line education, Educational pedagogy, Global business, College student preferences

\section{BACKGROUND}

$\mathscr{I}$

ntroduction to Global Business, BADM 101, was introduced in the lower division core of the College of Business (COB) curriculum at CSU Chico a decade ago as part of an AACSB review inspired revision. The course was designed and is delivered as an activity based pedagogy. Research documenting the success of the pedagogy has been published (Levine \& Guy, 2007). The course is also part of the university's cohort link program and research has shown the success of the program in regard to student learning and graduation rates (Levine \& Guy, 2004, 2006).

The course is intended for first semester freshmen and has built into the activities many non-content elements involving skill development for the study of business and enculturation into the COB student world. One of the problems encountered in the course over the past decade has been the necessity to enroll a certain percentage of upper division students into a course primarily designed for freshmen. This occurs either because junior college transfer students have not taken an equivalent course or because a student has changed their major midstream and thereby must go back and complete the $\mathrm{COB}$ lower division core requirements. These juniors and occasional seniors were often confused at best and other times disturbed by the requirement. Half of the 10 activities are group based and this caused further potential disruption regarding group formation.

As a possible means of addressing the problem a decision was taken to explore the development and delivery of an online version of the course. It was understood that the technology to deliver an academically professional course was available and that the college had the faculty to do so. Registration into the online version would be voluntary and restricted to students having completed 45 or more units. Before implementing the course, faculty decided to collect data from students in the spring 2008 that had just completed traditional in class sections of the course. Although faculty realized that online education had matured and was utilized across the country, they still wanted to get feedback from our students before implementing such a substantial change in the manner of 
instruction in a lower division core course. Thus students were surveyed as to whether or not they would have preferred to have taken the course on-line if the option had been available.

\section{ON-LINE EDUCATION}

Much has been written about on-line education. Topics have included: 1) the growth of on-line education, 2) the availability of technology to deliver such programs, 3) the quality of on-line education within a traditional university and its associated costs, and 4) the role of on-line education and training within the business sector. However, very little has been written regarding student receptivity to on-line education in comparison to a traditional classroom setting.

Enrollment in online-education courses has grown a great deal in the past decade. A 2003 survey of approximately 1,200 colleges and universities revealed that 1.9 million students were enrolled in online courses in the fall of 2003, 19 percent more than a year earlier (Carlson, 2004). Furthermore, online MBA programs are among the fastest growing fields of study online but not without experiencing growing pains. Many schools adapted online education for their MBA programs without doing much planning. Yet despite the apparent lack of planning in the early days, online MBA courses have not only caught on but have apparently become increasingly effective (Rice, 2000). Online education is now part of most universities around the country and has been "deeply integrated in higher education" (Survey of Higher Education, 2005). In general, courses have improved from the early days when students saw online education as an easy way to earn a grade. In some cases, the opposite appears to be true. "Rigor is just as possible online, because students are judged by the ability to communicate electronically and must demonstrate understanding of the course material on assignments other than closed book tests". (Bocchi, Eastman, $\&$ Swift, 2004).

The State of Georgia has instituted a joint online MBA program; the Georgia WebMBA ${ }^{\circledR}$. It is joint program of five AACSB universities: 1) Georgia College and State University, 2) Georgia Southern, 3) Kennesaw State, 4) the State University of West Georgia and 5) Valdosta State. The program includes 10 courses and admits 35 students per cohort (The Georgia WebMBA, 2005). Thus far four cohorts have moved through the program, with a retention rate of $87 \%$, indicating at least some good acceptance of the online education. (Bocchi, Eastman \& Swift, 2004)

Overall, student attitudes toward online courses appear to be quite positive. An early study of 500 online MBA students in three separate programs was revealing. The sample only had $56 \%$ access to the Internet at home (McGorry, 2002). Yet, despite the lack of access to the Internet at home, the response was positive. Students believed they "learned just as much as they would have had the courses been taught in a traditional classroom setting" (McGorry, 2002). Furthermore student attitude toward the course was overwhelming positive, most of the students believed that understanding the Internet was crucial to their future success, so they, in general, felt quite good about their experience. The chief drawback, according to these students, was the lack of interaction (McGorry, 2002).

Yet in the space of just three years, student attitudes appeared to change. Whereas the students in the 2002 study focused on the use of Internet as an end in and of itself, students in a 2005 study for an online statistics course at the University of Missouri expressed a good deal of dissatisfaction.

Although students in the Web course learned statistics as well as students in the traditional classroom, the results of the research indicated that the Web students were generally less satisfied with the course than those in the traditional classroom, despite the fact that the instructor, a statistics professor with 20 years of experience, was the same professor for both the face-to-face class and the Web class (Summers, et al., 2005).

The study was quite intriguing due the fact that the instructor tried to teach the online class in the same way as the traditional classroom, making as few changes as possible. The students somehow sensed a lack of enthusiasm on the part of the instructor which may have been due to the inability of the professor to convey the same feelings online as off (Summers, et al., 2005). Therefore, the authors came up with a number of suggestions for making future classes more satisfactory for the students. 
On the basis of the outcome of this study as well as the literature in online education, the following suggestions may help to minimize those differences for future students: (1) establish a pedagogical framework before course development, preferably one that lends itself to constructivist theory; (2) explicitly state grading procedures when assigning homework, projects, and tests; (3) hold office hours on the phone as well as online so that students have increased access to the instructor; (4) make a concerted effort to portray enthusiasm for the content and make it as meaningful as possible so that students are genuinely interested in learning the content; and (5) utilize real-time, on-line discussion periods for student and instructor interaction to help make students engage with each other and feel like an important part of the class (Summers, et al., 2005).

Online education remains a controversial topic despite its continuing widespread adoption both in the United States and Western Europe. This is in spite of the fact that the technology is now thoroughly accepted in higher education and the basic functions of delivering an online course are a normal part of most university curricula (Survey of Higher Education, 2005). A recent study by David D. Smith and Daryl J. Mitry of National University in California explores the controversy:

The technology of online learning has matured... However, the current direction is towards depreciation of faculty and lower academic standards. If faculty members everywhere do not assert their claim to real quality standards, and simultaneously show with their administrations how to properly compete and prosper, the public and scholars will both lose. (Smith \& Mitry, 2008).

The authors speak to the very real fear that online education might cheapen the academic experience, yet the literature to date does not bear this contention out. An early study compared traditional in class and online courses with very similar learning goals. The study included 53 colleges with AACSB accreditation. The study "found no significant differences in outcomes between classroom and online learners with an equal standards pedagogical model" (Duus \& Nielsen, 1999).

Smith and Mitry also examined the cost of online versus in class education. An analysis of the cost of operating online programs revealed that they actually were more expensive than large classrooms which ran contrary to expectations.

For universities, the fixed cost of classrooms is not a consideration in the comparison of online classes versus on ground classes. The buildings have previously been amortized. What remains are the variable costs of instruction of which the primary expenses are faculty compensation. Furthermore no significant economies of scale exist for online programs because the major cost is not infrastructure but the variable cost of the hours spent by faculty members. (Smith\& Mitry, 2008).

The authors do clarify by differentiating between the cost effectiveness of large classrooms versus the per capita variable costs which are higher in small classrooms.

Nonetheless, they are skeptical of quality and feel that it is sacrificed for the sake of profits.

Educators can lower costs, but only by lowering the quality of the primary resource, thereby reducing the variable expense. If all teaching faculty members have earned doctoral degrees from ranking universities-not lesser degrees from nonacademic universities or credits from the workplace - then costs may appear higher for online programs versus on-ground programs (Smith \& Mitry 2008).

Colleges of business should also note the emerging role of on-line education in the business world. Venture capitalists who specialize in the web perceive a different world looking forward. Union Square Ventures is a company that specializes in early stage investment in the Web. They see the brick and mortar classroom model as being an anachronism.

With access to course materials, ability to watch lectures and even tutor at a distance, we believe that we are only at the beginning of the web's impact on the fundamental structure of education. We expect much of that change to be 
away from the existing educational institutions and towards empowering individuals and newly-formed groups (Wenger, 2008).

Furthermore throughout the business world itself, so-called e-learning is being adopted at a rapid pace. Indeed, many banks today are using an advanced form of what can only be called activity-based learning to expedite employee training and retraining. Beneficial Bank in Philadelphia makes extensive use of specifically designed software, both on and offline, where employee training in different areas of banking is crucial due to the constantly changing nature of the banking world (Scarborough, 2008). learning:

A study by D. Hartley summarizes additional convincing arguments for corporate adoption of online

- $\quad$ availability, 24 hours a day

- $\quad$ affinity, attractive to companies and individuals interested in new technologies

- relevance

- $\quad$ efficiency

- $\quad$ sole option

- $\quad$ immediate reinforcement

- $\quad$ immediate feedback

- $\quad$ reduced cost

(Hartley, 2000)

There can be no doubt that online learning, particularly in business, is here to stay. The modern business student must be prepared to learn online if not at college then certainly in his or her future place of employment. More and more companies are adopting online learning strategies and believe that it will provide them with a competitive advantage. (Smith \& Rupp, 2004).

\section{THE PRESENT STUDY}

\section{Impetus}

The impetus for the present study was to improve student composition in the lower division core course "Introduction to Global Business". The course is designed for first semester freshmen and has many non-content goals and objectives particularly as they pertain to providing students with an insight into the college of business, it options and career choices, as well as the prevailing student culture. Do in part to enrollment procedures set in place by the State of California and to student decisions to change majors in midstream, students of junior or senior standing were often times enrolled with freshmen in the same section. To ameliorate the situation, it was decided to explore the development of an on-line delivery of the course with voluntary enrollment of students that had completed 45 or more semester units. Thus, it was decided to survey students who had just completed a traditional classroom version of the course to gain their insight.

\section{The Objective of the Study}

The objective of the study was twofold. First, the study investigates whether pre-business students, after having completed a traditional in class "Introduction to Global Business" course, designed for first semester freshmen, express a difference in preference for such a course to be delivered online versus classroom or no preference at all. Second, the study investigates whether four variables: 1) number of units of college credit completed, 2) anticipated grade in the class, 3) gender, and 4) age are related to students' preference for mode of instruction. 


\section{The Hypotheses}

The above mentioned objectives resulted in the following hypotheses:

$\mathbf{H}_{1}$ : Students have a preference for either online instruction or the traditional classroom (as opposed to no preference) without regard to any other variable.

$\mathbf{H}_{2}$ : The four variables - 1) number of units of college credit taken, 2) gender, 3) anticipated grade in the course, and 4) age - have an influence on a student's preference for online versus classroom instruction.

Other hypotheses would arise depending on which of the four variables in $\mathrm{H}_{2}$ are statistically significant.

\section{The Sample}

Two hundred fifty students took the final exam in 6 sections of BADM 101. Eleven students turned in a blank survey, for a total of 239 usable surveys. The 6 sections were taught by 4 different instructors during the spring 2008 semester.

\section{The Instrument}

The survey was comprised of one question which solicited student response to the following question: "Now that I have taken BADM 101, I wish I could have taken it online instead of in the traditional classroom". Response options were in the form of a Likert Scale with "1" strongly disagree (strongly prefer traditional classroom, " 5 " strongly agree (strongly prefer online), and " 3 " no preference. Data was also collected on "number of units completed as of the end of this semester", gender, age, and "anticipated grade in the course".

\section{The Results}

There were 239 surveys which included a response to the main question about online versus traditional instruction. However, a very few students did not respond to one of the other questions, so some results show a sample size less than 239 .

The first hypothesis is:

$\mathbf{H}_{1}$ : Students have a preference for either online instruction or the traditional classroom (as opposed to no preference) without regard to any other variable.

If this hypothesis is true, then the mean response would be either less than 3 or greater than 3 , or in symbols: $\mathrm{H}_{1}: \mu \neq 3$. The mean questionnaire response is 3.234 ,

Table 1-Online Preference Score

\begin{tabular}{|l|c|c|}
\hline \multicolumn{1}{|c|}{ Student Response } & $\#$ & $\%$ \\
\hline 5-strongly prefer online & 58 & 24.3 \\
4-mildly prefer online & 60 & 25.1 \\
3-no preference & 45 & 18.8 \\
2-mildly prefer traditional & 32 & 13.4 \\
1-strongly prefer traditional & 44 & 18.5 \\
\hline Total & 239 & 100 \\
\hline
\end{tabular}

which is statistically different from $3\left(\mathrm{t}_{238}=2.534\right.$, p-value $\left.=.0019\right)$. We conclude that students do have a preference and that preference is that they wish they could have taken the course online. We note, however, that this preference, though statistically significant, is weak since the mean response is 3.234 , which is much closer to the "no preference" category than the "mildly prefer online" category. 
Another way to look at the data (see Table 1) is that $49 \%$ of students had a mild or strong preference for online, $19 \%$ had no preference, and $32 \%$ had a mild or strong preference for traditional instruction.

Conclusion to $\mathbf{H}_{\mathbf{1}}$ : The students had a weak preference for online instruction.

The second hypothesis is:

$\mathbf{H}_{2}$ : The four variables - 1) number of units of college credit taken, 2) gender, 3) anticipated grade in the course, and 4) age - have an influence on a student's preference for online versus classroom instruction.

A regression analysis using the online preference response as the dependent variable and the above four variables as the independent variables revealed that number of units of college credit taken $(p$-value $=.0348)$ and anticipated grade in the course $(\mathrm{p}$-value $=.0097)$ are statistically significant, while gender $(\mathrm{p}$-value $=.6502)$ and age $(\mathrm{p}$-value $=.5598)$ are not. We note that though the overall regression was statistically significant $(\mathrm{p}$-value $=.0044)$, the R-square for the regression is only .0663. A regression using only the two significant variables (\# units, anticipated grade) shows an R-square of .0640 (p-value $=.00065)$. This indicates that only $6.40 \%$ of the variation in online preference response is explained by variation in the number of units of college credit and anticipated grade in the class. This low R-square is not surprising since there is usually substantial variation in people's preferences, and it is often difficult to find any variables that are strongly related to preference.

Conclusion to $\mathbf{H}_{2}$ : The variables number of units of college credit taken and anticipated grade in the course are statistically significantly related to students' preference for mode of instruction. This relationship, however, is weak. The variables age and gender are not related to students' preference for mode of instruction.

This conclusion leads to two other hypotheses, the first of which is:

$\mathbf{H}_{3}$ : The online preferences are different among freshmen, sophomores, juniors, and seniors. If so, we want to determine which groups have different preferences.

An analysis of variance showed that there are differences in the mean online preference responses of the four groups $\left(\mathrm{F}_{3,232}=3.50\right.$, p-value $\left.=.0162\right)$. From the means in Table 2, it appears that freshmen and sophomores have no preference and seniors have almost a mild preference for online. A comparison of the four means using Tukey's HSD method (honestly significant difference) shows (using $\alpha=.05$ ) that, indeed, the preference for online instruction among the seniors is stronger than that among the freshmen and the sophomores.

Table 2-Online Preference Score by Class Level

\begin{tabular}{|c|c|c|c|c|c|}
\hline & Fresh & Soph & Jr & Sr & Total \\
\hline $\mathrm{n}$ & 66 & 85 & 60 & 25 & 236 \\
mean & 3.030 & 3.059 & 3.483 & 3.920 & \\
\hline
\end{tabular}

Conclusion to $\mathbf{H}_{3}$ : Seniors have almost a mild preference for online instruction as opposed to traditional instruction and this preference for online is statistically greater than that for freshmen and sophomores, which are right at neutral. It is not possible to differentiate the juniors' online preference from either the seniors or the freshmen and sophomores.

The fourth and last hypothesis is:

$\mathbf{H}_{4}$ : Online preferences are different among those who anticipate different grades in the course.

To answer this question, we look at the anticipated grades using four groups: A; B; C; and C-, D, or F. We include the grade of $\mathrm{C}$ - in with the $\mathrm{D}$ and $\mathrm{F}$ since students who want to be business majors must make a grade of a straight $\mathrm{C}$ or better in the course. An analysis of variance shows that there are differences in the mean online preference responses of these four anticipated grade groups $\left(\mathrm{F}_{3,235}=2.586\right.$, $\mathrm{p}$-value $\left.=.0539\right)$. As we see in Table 3 , 
those who anticipate a grade of A have no preference-i.e., they are satisfied with their experience in the class. As the anticipated grade gets lower, the preference for online gets stronger. This makes sense because it is logical for students who like their grades to be neutral, and those students who did not like their grades would naturally tend to prefer something else.

Table 3-Online Preference Score by Anticipated Grade Using Four Grade Categories

\begin{tabular}{|c|c|c|c|c|c|}
\hline Anticipated Grade & A & B & C & C-,D,F & Total \\
\hline $\mathrm{n}$ & 73 & 126 & 36 & 4 & 239 \\
mean & 2.993 & 3.258 & 3.472 & 4.75 & \\
\hline
\end{tabular}

Conclusion to $\mathbf{H}_{4}$ : There are differences in the mean online preference responses for students who anticipated different grades in the course. In general, students who anticipated higher grades tended to have no preference between online instruction and the traditional classroom. This may be because they were satisfied with their grades and therefore their class experience. Students who anticipated lower grades tended to prefer online instruction. This may be because they did not like their grades and wished they could have had some different learning experience.

\section{CONCLUSION}

Overall, a weak preference for taking the course online was determined. Important to the purpose of the research was the finding that class standing was significantly related to that preference and that this was most so for seniors and juniors. Due to this result the faculty decided to proceed and develop an online version of the course specifically to be offered to juniors and seniors on a voluntary basis.

\section{FUTURE RESEARCH}

Data will be collected from students at the completion of the online version of the course. Analyses will examine their online experience and whether they would have preferred to have taken the course in a traditional classroom setting. The course is focused on activity based learning. Thus, research will also be conducted to examine the success of the pedagogy comparing the online with the in class versions.

\section{AUTHOR INFORMATION}

Dr. Mark Levine is Professor of Management and was the Founding Director of the Academy for International Business, College of Business, California State University, Chico. He has published more than fifty journal articles and conference proceedings on such diverse topics as global business, educational pedagogy, and management of change. Dr. Levine has consulted to numerous Fortune 500 companies both domestic and overseas including Trans America Co., Exxon Co., Siemens Automation North America Co., and Siemens AG.

Paul W. Guy joined the CSU, Chico business faculty in 1979 after receiving his PhD in statistics from Texas A\&M University. He has taught courses in business statistics, quantitative business analysis, and productions and operations management. He was recognized for teaching excellence in 1987-1988 as the recipient of the Outstanding Teaching Performance Award from the Inter-Business Student Council. His research interests include business statistics and the teaching of business. Published papers have appeared in Accounting Education: An International Journal, The International Journal of Finance, and Journal of College Teaching \& Learning among others.

Peter Straus is adjunct faculty in the Department of Management, College of Business, CSU Chico. He has taught the Introduction to Global Business course since 2002. Prior to that Mr. Straus spent 26 years in a variety of roles at AVL Looms Inc., a global manufacturer and marketer of looms, software, and weaving accessories, located in Chico, California. Mr. Straus stepped down as CEO in 2004 and is currently executive vice president of the company. Mr. Straus is a graduate of the University of Michigan in Ann Arbor Michigan.

HT Levine is Adjunct Faculty in the Department of Management, College of Business, CSU Chico. She is the creator and instructor of the online version of the Introduction to Global Business course. Helen has held executive 
positions at several successful internet companies and currently works as in independent consultant. Ms. Levine has a MS in Computer Science from CSU Chico.

\section{REFERENCES}

1. Bocchi, J., Eastman, J., and Swift, C. (2004). Retaining the Online Learner: Profile of Students in an Online MBA Program and Implications for Teaching Them. Journal of Education for Business, 79(4), r2004r2253.

2. Carlson, S. (2004). Online education survey finds unexpectedly high enrollment growth. The Chronicle of Higher Education, November 26.

3. Duus, H., and Nielsen, O. (1999). Der er en ny Verden til Forskel [Making a Difference]. Civilokonomen, $1,8-9$.

4. Hartley, D. (2000). All aboard the e-learning train. Training \& Development, 54(7), 37-42. Retrieved November 14, 2008, from ABI/INFORM Global database. (Document ID: 56408819).

5. Levine, M.F., and Guy, P.W., Activity Based Learning in a Freshman Global Business Course: Analysis of Preferences and Demographic Differences, Journal of College Teaching and Learning, v.4, No.8, August 2007.

6. Levine, M.F., and Guy, P.W., Freshman Linked Cohort Classes in the Study of Business: Results of Performance and Graduation in Business, Journal of College Teaching and Learning, v. 3, No.1, January 2006.

7. Levine, M.F., and Guy, P.W., Freshman Linked Cohort Classes in the Study of Global Business: A Comparative Analysis of Performance and Completion of the Lower Division Core, Journal of College Teaching and Learning, v. 1, No.1, January 2004.

8. McGorry, S. (2002, June). Online, but on target? Internet-based MBA courses: A case study. Internet \& Higher Education, 5(2), 167. Retrieved November 11, 2008, from Academic Search Premier database.

9. $\quad$ Rice, D. (2000). E-learning study has surprising results. IT Support News, 20(11), 22.

10. Scarborough, M. (2008). Community Banker; Vol. 17 Issue 1, p21-21, 1p.

11. Smith, D., and Mitry, D. (2008). Investigation of Higher Education: The Real Costs and Quality of Online Programs. Journal of Education for Business, 83(3), 147-152.

12. Smith, A., and Rupp, W. (2004). Managerial implications of computer-based online/face-to-face business education: a case study. Online Information Review, 28(2), 100-109.

13. Summers, J., Waigandt, A., and Whittaker, T. (2005, Spring2005). A Comparison of Student Achievement and Satisfaction in an Online Versus a Traditional Face-to-Face Statistics Class. Innovative Higher Education, 29(3), 233-250. Retrieved November 12, 2008, doi:10.1007/s10755-005-1938-x.

14. Survey of Higher Education. (2005) The brains business. The Economist, 376, 4.

15. The Georgia WebMBA. (2005). T+D, 59(9), 2005-2074.

16. Wenger, Albert. "Power to the People", http://www.unionsquareventures.com/2008/09/power_to_the_pe_1.html, accessed October 62008. 